\title{
Spatial distribution of microbial communities among colonies and genotypes in nursery-reared Acropora cervicornis
}

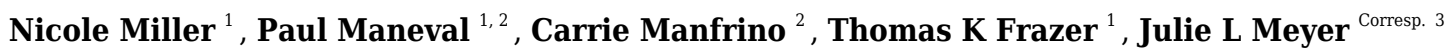 \\ ${ }^{1}$ School of Natural Resources and Environment, University of Florida, Gainesville, FL, United States \\ 2 Little Cayman Research Center, Central Caribbean Marine Institute, Little Cayman, Cayman Islands \\ 3 Soil and Water Sciences Department, Genetics Institute, University of Florida, Gainesville, FL, United States \\ Corresponding Author: Julie L Meyer \\ Email address: juliemeyer@ufl.edu
}

Background. The architecturally important coral species Acropora cervicornis and A. palmata were historically common in the Caribbean, but have declined precipitously since the early 1980s. Substantial resources are currently being dedicated to coral gardening and the subsequent outplanting of asexually reproduced colonies of Acropora, activities that provide abundant biomass for both restoration efforts and for experimental studies to better understand the ecology of these critically endangered coral species.

Methods. We characterized the bacterial and archaeal community composition of $A$. cervicornis corals in a Caribbean nursery to determine the heterogeneity of the microbiome within and among colonies. Samples were taken from three distinct locations (basal branch, intermediate branch, and branch tip) from colonies of three different coral genotypes.

Results. Overall, microbial community composition was similar among colonies due to high relative abundances of the Rickettsiales genus MD3-55 (Candidatus Aquarickettsia) in nearly all samples. While microbial communities were not different among locations within the same colony, they were significantly different between coral genotypes. These findings suggest that sampling from any one location on a coral host is likely to provide a representative sample of the microbial community for the entire colony. Our results also suggest that subtle differences in microbiome composition may be influenced by the coral host, where different coral genotypes host slightly different microbiomes. Finally, this study provides baseline data for future studies seeking to understand the microbiome of nurseryreared $A$. cervicornis and its roles in coral health, adaptability, and resilience. 
1 Spatial distribution of microbial communities among

2 colonies and genotypes in nursery-reared Acropora

3 cervicornis

4

5

6

7

8

9

10

11

12

13

14

15

16

17

18

19

20

21

22

23

24

25

26

27

28

29

30

31

32

33

34

35

36

37

38

39

\author{
Nicole Miller ${ }^{1}$, Paul Maneval ${ }^{1,2}$, Carrie Manfrino ${ }^{2}$, Thomas K. Frazer ${ }^{1}$, Julie L. Meyer ${ }^{3}$ \\ ${ }^{1}$ School of Natural Resources and Environment, University of Florida, Gainesville, FL, USA \\ ${ }^{2}$ Central Caribbean Marine Institute, Little Cayman Research Center, Little Cayman, Cayman \\ Islands \\ ${ }^{3}$ Soil and Water Sciences Department, Genetics Institute, University of Florida, Gainesville, FL, \\ USA
}

Corresponding Author:

Julie Meyer ${ }^{3}$

2033 Mowry Rd, Gainesville, FL, 32611, USA

Email address: juliemeyer@ufl.edu

\title{
Abstract
}

Background. The architecturally important coral species Acropora cervicornis and A. palmata were historically common in the Caribbean, but have declined precipitously since the early 1980s. Substantial resources are currently being dedicated to coral gardening and the subsequent outplanting of asexually reproduced colonies of Acropora, activities that provide abundant biomass for both restoration efforts and for experimental studies to better understand the ecology of these critically endangered coral species.

Methods. We characterized the bacterial and archaeal community composition of A. cervicornis corals in a Caribbean nursery to determine the heterogeneity of the microbiome within and among colonies. Samples were taken from three distinct locations (basal branch, intermediate branch, and branch tip) from colonies of three different coral genotypes.

Results. Overall, microbial community composition was similar among colonies due to high relative abundances of the Rickettsiales genus MD3-55 (Candidatus Aquarickettsia) in nearly all samples. While microbial communities were not different among locations within the same colony, they were significantly different between coral genotypes. These findings suggest that sampling from any one location on a coral host is likely to provide a representative sample of the microbial community for the entire colony. Our results also suggest that subtle differences in microbiome composition may be influenced by the coral host, where different coral genotypes host slightly different microbiomes. Finally, this study provides baseline data for future studies 
40 seeking to understand the microbiome of nursery-reared $A$. cervicornis and its roles in coral

41 health, adaptability, and resilience.

42

\section{Introduction}

44 Historically, Acropora cervicornis and A. palmata corals were the most abundant corals 45 throughout the broader Caribbean region [1-3]. Since 1980, an estimated $97 \%$ of native 46 populations of Acropora corals have diminished throughout the Caribbean [4], with large losses 47 attributed to the microbially mediated white-band disease [5]. Both $A$. cervicornis and $A$. 48 palmata are now listed as critically endangered by the IUCN [6] and threatened under the 49 Endangered Species Act [7], providing a legal mandate to facilitate the recovery of these 50 keystone species. Ecologically, repopulation of Acropora corals is critical for improving the 51 health of entire reef systems because they contribute to reef accretion and provide structural complexity that serves as important habitat for fish and other reef organisms.

In response to the loss of coral reefs, organizations around the Caribbean have turned to coral gardening to replenish local populations of coral $[8,9]$. For example, coral restoration projects have resulted in the outplanting of tens of thousands of nursery-reared Acropora corals on Florida reefs each year $[10,11]$. These restoration efforts rely primarily on the asexual reproduction of these corals as small coral fragments grow at faster rates than larger colonies [12] and sequential fragmentation, which mimics natural breakage cycles, can provide more new coral colonies for restoration than could be produced through sexual reproduction in the same time frame. Fragmented corals rapidly grow in in situ ocean nurseries and are then outplanted back to reefs, a method that has proven to be highly effective for producing abundant $A$. cervicornis biomass. This improved growth and decreased mortality of $A$. cervicornis in ocean nurseries in comparison corals attached to reefs is due in part to reduced predation by the corallivorous snail Coralliophila abbreviata and the fireworm Hermodice carunculata [9]. In addition to the direct effects of predation on colony health, C. abbreviata is a known vector for white-band disease [13] and H. carunculata is a known vector for the coral pathogen Vibrio shilohi [14].

However, the survival of Acropora corals once placed back on the reef is often lower than desired given the resource-intensive nature of nursery production [15-17]. Survival of restored Acropora is also highly variable among sites $[10,18]$, suggesting that some environments may be better than others for long-term restoration efforts. To date, research has focused on optimizing out-planting techniques and measuring performance of different coral genotypes [12, 19-22], while few studies have examined the microbial community composition associated with the success of outplanted corals. Given the critical role of the microbiome in both the health and disease of corals [23-25], manipulation of the coral microbiome has recently been proposed as a way to increase the resilience of corals [26-28] and improve restoration efforts [29,30]. Several 79 recent review papers $[24,26,31-33]$ have detailed the potential roles that the microbiome plays 
80

81

82

83

84

85

86

87

88

89

90

91

92

93

94

95

96

97

98

99

100

101

102

103

104

105

106

107

108

109

110

111

112

113

114

115

116

117

118

119

in the overall health of the coral holobiont, including protection against pathogens, tight recycling of nutrients within the holobiont, and nitrogen fixation, which benefits the photosynthetic dinoflagellate symbionts, and there is growing interest in designer microbes and probiotic strains to mitigate loss of coral reefs $[26,27,34,35]$.

Even as our ability to characterize coral microbial communities has become exponentially faster and cheaper due to technological advances in DNA sequencing, the availability of natural corals for study has drastically decreased. Leveraging access to abundant biomass in nursery-reared corals with known genotypes, we address two basic questions about the spatial distribution of coral microbial communities. First, we assess whether a single sample is representative of the microbiota across an entire colony, information that is useful for both researchers and resource managers that strive to reduce stressors to already threatened species. To date, only a handful of studies have assessed spatial distribution of the microbial communities within coral colonies. Spatial heterogeneity was observed using bacterial community fingerprinting methods in branching Porites furcata between branch tips and branch bases [36] and across mounding Orbicella annularis corals [37]. In contrast, pyrosequencing in A. palmata showed no statistical difference in bacterial communities from the top, underside, and base of the colonies, regions with distinct irradiance levels [38]. Second, we address whether the microbial community changes with coral genotype. Given the limited number of extant natural populations of $A$. cervicornis in many parts of the Caribbean, there are limited studies of its microbial community composition. Previous studies of natural populations have shown that the microbiota of $A$. cervicornis in Puerto Rico varied between deep and shallow sites [39] and that intercolony variation of A. cervicornis in Panama was weaker than seasonal variation [40]. However, variation of bacterial communities in A. cervicornis from Panama used in a disease transmission study demonstrated that colony had a stronger effect than collection site [41]. Here, we apply an extensive sampling scheme to A. cervicornis in ocean nurseries in the Cayman Islands to examine the spatial distribution and heterogeneity of $A$. cervicornis microbial communities.

\section{Materials \& Methods}

Sample Collection. Field collections were authorized by permit from the Department of Environment on behalf of the National Conservation Council, Cayman Islands to CM and TF (December 1, 2017 to December 1, 2018). Coral colonies for this study were sampled at the

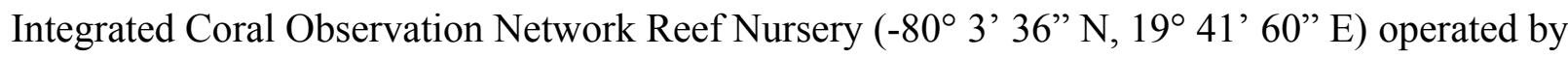
the Central Caribbean Marine Institute (CCMI) in Little Cayman. The nursery uses a coral gardening technique $[11,12]$ on $\mathrm{PVC}$ trees and frames to cultivate $A$. cervicornis at 18 meters depth, under conditions of natural currents, temperatures, and light. Three previously identified coral genotypes determined via genotyping-by-sequencing [42], herein referred to as green (G), red (R), and yellow (Y) genotypes, were sampled from the nursery. Colonies of these genotypes were added to the CCMI nursery in 2012 as fragments from local populations. Each colony was fragmented from a larger coral colony in 2016, approximately one and a half years prior to

PeerJ reviewing PDF | (2020:04:48378:1:1:NEW 3 Jul 2020) 
120

121

122

123

124

125

126

127

128

129

130

131

132

133

134

135

136

137

138

139

140

141

142

143

144

145

146

147

148

149

150

151

152

153

154

155

156

157

158

159

sampling. Colonies used in this study had no apparent signs of disease or illness at the time of sample collection. Colonies observed 10 months after sampling showed no signs of disease or distress (Figure 1).

All in situ collection was completed on December 8, 2017 by AAUS-certified science divers. The coral microbial community was sampled from three colonies each of three coral genotypes. All 9 colonies hung within 1 meter of each other on the same frame structure (Figure 1). On each colony, three replicate samples were collected from each of the following locations: basal branches $\left(1^{\circ}\right)$, intermediate branches $\left(2^{\circ}\right)$, and apical colony tips $\left(3^{\circ}\right)$, for a total of 81 coral surface samples. After brief agitation by a needleless syringe, the surface mucus layer and coral tissue was aspirated with a sterile $60-\mathrm{ml}$ syringe. Collections were transported back to the CCMI laboratory within the hour. Syringes were positioned vertically for about five minutes to allow the coral sample material to settle at the tip of the syringe. Coral mucus and tissues were transferred to sterile 2-ml cryotubes, centrifuged at 13,000 rpm for 5 minutes, and the saltwater supernatant was decanted. Lastly, 5 volumes of RNAlater (Ambion, Austin, TX) to 1 volume sample pellet was added to the cryotube. Samples were incubated at $4^{\circ} \mathrm{C}$ for 12 hours and then stored at $-20^{\circ} \mathrm{C}$ until nucleic acid extraction.

V4 Amplicon Library Preparation. DNA was extracted from up to $0.5 \mathrm{ml}$ of mucus and tissue using a DNeasy Powersoil Kit (Qiagen, Germantown, MD) according to the manufacturer's instructions, including bead beating for 10 minutes. As extraction controls were not collected when samples were processed in early 2018, we acknowledge the potential for contamination from lab reagents [43], either in the extraction kit or in subsequent PCR and cleanup reagents. The processing of extraction controls has since become standard practice in our lab beginning in mid-2018. After DNA extraction, guidelines of the Earth Microbiome Project 16S Illumina Amplicon Sequencing Protocol [44] were followed for amplicon sequencing preparation using the 2015-current primer set with barcoded forward primer 515FB [45] and reverse primer 806RB [46]. targeting Bacteria and Archaea. The V4 region of the 16S rRNA gene was amplified in three replicate $25-\mu 1$ reactions for each coral sample using Phusion High-Fidelity PCR Master Mix (New England Biolabs, Ipswich, MA), 3\% dimethyl sulfide, $0.25 \mu \mathrm{M}$ of each primer, and roughly $10 \mathrm{ng}$ of DNA template. PCR cycling was as follows ( 35 cycles): 45 seconds at $94^{\circ} \mathrm{C}$ denaturation, 60 seconds at $50^{\circ} \mathrm{C}$ annealing, 90 seconds at $72^{\circ} \mathrm{C}$ extension. Initial denaturation and final extension were for 3 minutes at $94^{\circ} \mathrm{C}$ and 10 minutes at $72^{\circ} \mathrm{C}$, respectively. Negative PCR controls were examined by gel electrophoresis on ethidium bromide-stained $1 \%$ agarose gels to ensure no contamination. Triplicate PCR products were then combined and purified using a MinElute PCR Purification Kit (Qiagen). Cleaned amplicon library concentrations were determined with a Nanodrop 1000. A total of $240 \mathrm{ng}$ of each amplicon library was pooled for sequencing using an Illumina MiSeq with paired 150-bp reads (v.2 cycle format) at the University of Florida Interdisciplinary Center for Biotechnology Research. 
160

161

162

163

164

165

166

167

168

169

170

171

172

173

174

175

176

177

178

179

180

181

182

183

184

185

186

187

188

189

190

191

192

193

194

195

196

197

198

199

Analysis of V4 Amplicon Libraries. Illumina adapters and primers were removed using cutadapt v. 1.8.1 [47]. Additional processing and analysis of amplicon libraries was completed in R v. 3.5.1. Quality filtering, error estimation, merging of reads, dereplication, removal of chimeras, and selection of amplicon sequence variants (ASVs) were performed with DADA2 v. 1.10.0 [48] as in [49], using the filtering parameters truncLen $=c(150,150)$, $\operatorname{maxN}=0$, $\operatorname{maxEE}=\mathrm{c}(2,2)$, truncQ $=2, \mathrm{rm}$.phix $=\mathrm{TRUE}$ to remove all sequences with ambiguous basecalls and phiX contamination. Taxonomy was assigned in DADA2 to ASVs using the SILVA reference dataset v. 132 [50]. Sequences that could not be assigned as bacteria or archaea and sequences identified as chloroplasts or mitochondria were removed from further analysis.

The ASV and taxonomy tables, along with associated sample metadata were imported into phyloseq v. 1.26.0 [51] for community analysis. ASVs with counts across all samples of less than 5 were removed from the analysis. ASVs with zero counts were transformed using the count zero multiplicative method with the zCompositions package v. 1.1.2 in R [52]. The zero-replaced read counts were transformed with the centered log-ratio transformation and the Aitchison distance metric was calculated with CoDaSeq v. 0.99.2 [53]. Principal components analysis of the Aitchison distance was performed with the package prcomp in R and plotted with ggplot $2 \mathrm{v}$. 3.1.0 [54]. Analysis of similarities (ANOSIM) was performed on the Aitchison distance using the R package vegan v. 2.5-3 [55]. Differential abundance of microbial families among coral genotypes was determined with Analysis of Composition of Microbiomes (ANCOM) [56] as in [49], using an ANOVA significance level of 0.05 and removing families with zero counts in $90 \%$ or more of samples. Only families detected in at least $70 \%$ of samples were reported. All metadata and R scripts used for analysis are available in Github (github.com/meyermicrobiolab/Microbiomes-of-nursery-reared-Acropora-cervicornis).

\section{Results}

A total of 81 amplicon libraries were analyzed from nine separate coral colonies representing three genotypes of $A$. cervicornis. After quality control, libraries contained an average of 77,923 reads and ranged from 432-184,540 reads (Table S1). Sequencing reads with primers and adapters removed are available at NCBI's Sequence Read Archive under BioProject PRJNA495377. Overall, nursery-reared A. cervicornis microbial communities were similar within colonies and did not differ statistically by branch location (ANOSIM R $=0.024, \mathrm{p}=$ 0.057 ). Microbial community composition varied by both coral genotype (ANOSIM R $=0.199, p$ $=0.001$ ) and by colony (ANOSIM $\mathrm{R}=0.264, \mathrm{p}=0.001$ ), although the effect size of each was relatively small. Microbial communities of yellow colonies appeared more distinct from microbial communities of the red and green coral genotypes (Figure 2).

The most abundant bacterial orders detected were Rickettsiales, Synechococcales, Vibrionales, and an unclassified order of Alphaproteobacteria (Figure 3). Both Rickettsiales and Synechococcales were detected in most samples. Diverse ASVs classified as Vibrionales were 
200

201

202

203

204

205

206

207

208

209

210

211

212

213

214

215

216

217

218

219

220

221

222

223

224

225

226

227

228

229

230

231

232

233

234

235

236

237

238

239

common and most abundant in the yellow genotype colonies. One abundant ASV from the unclassified order of Alphaproteobacteria common in corals of the green genotype was an exact match to an unpublished clone library sequence from $A$. palmata in Puerto Rico (GenBank Accession EU853842) and 99.6\% similar to a clone sequence (GenBank Accession AY323179) from healthy A. palmata in Barbados [57].

There were two samples with very distinct community structure: one sample from a basal branch $\left(1^{\circ}\right)$ on a red genotype colony and one sample from an apical tip $\left(3^{\circ}\right)$ on a yellow genotype colony (Figure 3, panels A, C). The unique sample taken from a red colony had a relative abundance of $38 \%$ for a single Alteromonadales ASV classified as Algicola, which was an exact match to a clone library sequence from a diseased Pavona duerdeni coral in Thailand (GenBank Accession KC527315) [58] as well as to several other marine sources. The unique sample taken from a yellow colony also had high relative abundances of two Alteromonadales ASVs, which were different from the predominant Alteromonadales ASV in the red colony. The first was an ASV classified as Thalassotalea (16\% relative abundance) that was an exact match to the type strain Thalassotalea euphylliae str. Eup-16 isolated from the coral Euphyllia glabrescens (GenBank Accession NR_153727.1) [59] and to clone libraries from the coral Galaxea fascicularis (GenBank Accession KU354186), crustose coralline algae (GenBank Accession JQ178640.1) [60], and the sponge Diacarnus erythraeanus (GenBank Accession HM854473.1) [61]. The second common Alteromonadales ASV in the red colony was an unclassified genus of Alteromonadaceae (11\% relative abundance) that was an exact match to several clone library sequences from corals, including Gorgonia ventalina (GenBank Accession GU118325) [62], Porites lutea (GenBank Accession KF179648) [63], Acropora pruinosa (GenBank Accession JQ347406), and a coral-encrusting sponge (GenBank Accession HM593584) [64]. The unique yellow colony sample was also distinguished by the high relative abundance $(27 \%)$ of one Opitutales ASV classified as Coraliomargarita and was 98\% similar to clone library sequences from the corals Porites lutea (GenBank Accession KF179779) [63] and Favia corals with Black Band Disease (GenBank Accession GU472376).

By far, the most abundant bacterial order in nearly all of the samples from this study was Rickettsiales. In total, there were 11 ASVs classified as Rickettsiales, including five ASVs classified as Rickettsiales genus MD3-55, one ASV classified as Rickettsiales family S25-593, and five ASVs classified as Rickettsiaceae. The two most abundant ASVs were both classified as genus MD3-55 and together these two ASVs averaged a relative abundance of $75 \%$ in all samples. The remaining 9 Rickettsiales ASVs collectively had an average relative abundance well below 1\%. The two most abundant MD3-55 ASVs (hereafter, ASV1 and ASV2, respectively) differed by a single nucleotide. ASV1 differed by one nucleotide in the V4 region of the 16S ribosomal RNA gene from the metagenome-assembled genome (GenBank Accession NZ_RXFM01000000) of an MD3-55 population from A. cervicornis collected in the Florida keys named Candidatus Aquarickettsia rohweri strain a_cerv_44 [65]. ASV2 was an exact match 
240 in the V4 region to the metagenome-assembled genome. According to BLASTn results, both 241 abundant Rickettsiales ASVs in all samples were also 99\% - 100\% identical to a clone library 242 sequence from healthy Caribbean Orbicella faveolata (GenBank Accession JQ516457) [66].

243

244

245

246

247

248

249

250

251

252

253

254

255

256

257

258

259

260

261

262

263

264

265

266

267

268

269

270

271

272

273

274

275

276

277

278

279

The distribution of the five Rickettsiales genus MD3-55 ASVs was strikingly different across the three coral genotypes (Figure 4). Only ASV1 was detected in all samples from the three green genotype colonies and all samples from one red genotype colony. The other two red colonies were predominately ASV2, along with lower levels of ASV3 and ASV4. All five of the MD3-55 ASVs were detected in the yellow colonies, which contained predominantly ASV2. To determine the consistency of this result, we repeated the entire analysis pipeline six times to calculate the relative abundance of the five MD3-55 ASVs across all samples and achieved identical results.

Given the high relative abundance of just two Rickettsiales ASVs across nearly all samples, the differences in microbial community composition among coral genotypes were based on microbes with low relative abundances. Sixteen microbial families were differentially abundant across coral genotypes (Figure 5). The largest difference among coral genotypes was in an unclassified family of Alphaproteobacteria (6 ASVs), corresponding to the unclassified order of Alphaproteobacteria that was common in green colonies (Figure 3). This Alphaproteobacteria family was most abundant in green colonies and least abundant in red colonies (Figure 5). As described above, the most abundant ASV in this family matched sequences previously detected in coral microbial communities. In contrast, the family Francisellaceae (4 ASVs) was most abundant in red colonies and least abundant in green colonies. The most abundant Francisellaceae ASV was 99.6\% similar to four clone library sequences (GenBank Accessions FJ202895, FJ202734, FJ202359, FJ202230) and more than 98\% similar to twenty additional clone library sequences from the same study on Caribbean Orbicella faveolata corals [67].

The microbial community composition of yellow colonies appeared distinct from both red and green colonies (Figure 2), which appears to be driven primarily by four differentially abundant bacterial families that were detected in higher abundances in the yellow colonies compared to red and green. These include Desulfobacteraceae, Pirellulaceae, Puniceicoccaceae, and Xenococcaceae (Figure 5). A total of four Desulfobacteraceae ASVs were detected in this study. The most abundant Desulfobacteraceae ASV was an exact match to clone library sequences from several coastal marsh habitats, including a clone library sequence (KF513059) associated with the "pink berry" consortia of sulfate-reducing bacteria and sulfur-oxidizing bacteria [68]. A total of two Pirellulaceae ASVs (phylum Planctomycetes) were detected at low abundance in most samples and these sequences matched clone library sequences from a variety of marine habitats. There were eight Puniceicoccaceae ASVs (phylum Verrucomicrobia) and the most abundant were classified as Coraliomargarita as discussed above and Lentimonas. The most abundant Lentimonas ASV was an exact match to many clone library sequences from marine habitats, including an unpublished sequence (MF039937) from the sponge Theonella. A total of four

PeerJ reviewing PDF | (2020:04:48378:1:1:NEW 3 Jul 2020) 
280

281

282

283

284

285

\section{6}

287

288

289

290

291

292

293

294

295

296

297

298

299

300

301

302

303

304

305

306

307

308

309

310

311

312

313

314

315

316

317

318

319

Xenococcaceae ASVs (phylum Cyanobacteria) were detected and the most abundant was almost entirely absent from red and green colonies. This ASV was classified as the genus Xenococcus PCC-7305 and was an exact match to clone library sequences from stromatolites in the Bahamas (EU249096) [69] and several unpublished clone library sequences from ooilitic sands in the Bahamas (JX255853, JX255856, JX255863, JX255892, JX504367, JX504398).

\section{Discussion}

By characterizing the microbial community composition of nine samples per coral colony, we have demonstrated that sampling from one location on an A. cervicornis coral colony is likely to provide a representative sample of the microbial community for the entire colony. This has important implications for researchers and resource managers who are concerned with how many samples are appropriate to take per colony and how to minimize sampling to reduce stress to colonies. It is also important to note that even with the heavy sampling that was performed here, namely nine samples taken in one day from a basketball-sized colony, no visible stress to the colonies was discernable. These colonies were observed during regular maintenance of the in situ nursery and roughly a year after sampling, all of the colonies were thriving. Our finding that one sample is likely representative of the whole colony is consistent with a similar analysis of $A$. palmata colonies that demonstrated microbial communities were not different between the topside of the wide branches of elkhorn coral and the more shaded underside of branches and colony bases [38]. Thus, for Caribbean acroporid corals, it appears that microbial community composition is relatively uniform at the colony scale. Since both of these coral species are critically endangered, this means that sampling for microbiota can be minimized to reduce impact to the coral host. However, this remains to be tested more broadly across different coral species, and especially in wild populations when available, rather than the relatively sheltered nursery-reared colonies sampled here.

These results seemingly conflict with earlier work using fingerprinting methods that detected spatial heterogeneity within colonies of Porites and Orbicella corals [36, 37]. It is possible that other coral groups exhibit more heterogeneity across colonies, however, this conflict may also be an artefact of the different methods used and the increased sample sizes of our study. For example, Rohwer et al. [36] used T-RFLP on a total of eight samples and Daniels et al. [37] used ARISA on a total of seventeen samples. While we did detect differences among samples (and a few samples were clearly very distinct), overall the differences among colonies and among genotypes were stronger than the differences within colonies. Therefore, heterogeneity does exist in the microbial communities across the surface of the coral colony regardless of coral species, but these differences are likely much smaller than differences among colonies.

Strikingly, the most abundantly detected sequences in this study belong to the Rickettsiales genus MD3-55. This is consistent with earlier work on natural populations of $A$. cervicornis, $A$. palmata, and A. prolifera at sites in Puerto Rico, Panama, and the Florida Keys [70]. Casas et al. 
320 [70] found high relative abundances of coral-associated Rickettsiales in clone libraries of near

321

322

323

324

325

326

327

328

329

330

331

332

333

334

335

336

337

338

339

340

341

342

343

344

345

346

347

348

349

350

351

352

353

354

355

356

357

358

359

full-length $16 \mathrm{~S}$ rRNA genes in both A. cervicornis and A. prolifera but were only able to detect

Rickettsiales using a targeted nested-PCR approach in A. palmata. Rickettsiales were also detected at low levels in natural populations of A. cervicornis and A. palmata in Panama using metabarcoding of the V6 hypervariable region [40]. More recent studies using metabarcoding of the V4 hypervariable region have detected very high relative abundances of Rickettsiales genus MD3-55 in natural populations of $A$. cervicornis in Puerto Rico [39] and in nursery-reared $A$. cervicornis (but not in $A$. palmata) from the Florida Keys [71]. In Florida nursery-reared $A$. cervicornis, experimental nutrient enrichment substantially increased the relative abundance of one Operational Taxonomic Unit of Rickettsiales [72]. Together, these results suggest that the Rickettsiales genus MD3-55 is common in Caribbean A. cervicornis and less common in $A$. palmata. The results also suggest that the predominance of MD3-55 may be impacted by the choice of PCR primer (V6 versus V4, for example) or that variation in the abundance of the presumably intracellular MD3-55 may be influenced by environmental conditions.

The role of the Rickettsiales genus MD3-55 in the health of acroporid corals is unclear. Here, we detected high relative abundances of this genus in all samples from nursery-reared colonies that exhibited no signs of disease in the year and a half prior to sampling and more than a year after sampling. However, this group was originally suspected to play a role in coral disease when intracellular bacterial aggregates were detected in histological slides of Acropora tissues with white-band disease (WBD) [73]. Subsequently, Rickettisales-like organisms, which can be detected by Geimsa stain, were detectable inside mucocytes of both healthy A. cervicornis and in WBD tissues [74, 75]. The presence of Rickettsiales in association with WBD in A. cervicornis has been confirmed by molecular methods, however, the relative abundance of Rickettsiales at times increased with the disease [76], and at times did not increase with the disease [77]. The recent recovery of a metagenome-assembled genome of the dominant MD3-55 strain detected by Casas et al. [70] and the widespread detection of MD3-55 sequences in both environmental samples and coral-associated microbial community datasets [65] have shed new light on the role of this apparently ubiquitous intracellular invertebrate symbiont.

The representative genome of MD3-55 from Caribbean A. cervicornis, dubbed Candidatus Aquarickettsia rohweri, has a reduced genome size, limited capacity for the biosynthesis of sugars and amino acids, and genes encoding nucleotide transport proteins, all of which are reflective of its intracellular, host-dependent lifestyle [65]. The Candidatus Aquarickettsia rohweri genome also has genes to sense extracellular nitrate levels, despite lacking genes to metabolize nitrogen. It has been hypothesized that Candidatus Aquarickettsia rohweri responds to environmental nitrate enrichment with increased growth, which saps the host of energy and makes it more susceptible to diseases like WBD [65]. However, to date strong empirical evidence is lacking for the connection between abundance of members of the genus MD3-55 (Candidatus Aquarickettsia) and quantifiable disease signs. This may, in part, be due to biases in

Peerj reviewing PDF | (2020:04:48378:1:1:NEW 3 Jul 2020) 
360

361

362

363

364

365

366

367

368

369

370

371

372

373

374

\section{5}

376

377

378

379

380

381

382

383

384

385

386

387

388

389

390

391

392

393

394

395

396

397

398

399

the production of $16 \mathrm{~S}$ rRNA gene amplicon libraries which may not correspond to true biological abundances in situ or it may reflect the indirect relationship between nutrient enrichment, abundance of MD3-55, and signs of disease in which a certain threshold of MD3-55 must be reached before host health is negatively affected.

Alternatively, there is the possibility that not all strains of MD3-55 are equally harmful to the host. Here, we detected two predominant strains of MD3-55 that varied across coral genotypes in addition to three minor strains. This is consistent with recent work demonstrating that while the genus Endozoicomonas was predominant among Acropora tenuis bacterial communities, individual ASVs of Endozoicomonas were highly host genotype-specific [76]. Similarly, Endozoicomonas strains were identified as sporadic symbionts in the Pacific Line Islands [78], where Endozoicomonas was found on Porites lutea from only one island out of six islands sampled. However, further study is required to determine if these strains have genomic differences between strains that result in functional differences that affect coral health.

\section{Conclusions}

We examined the heterogeneity of microbial communities within and among coral colonies and found that while some heterogeneity exists within samples from the same coral colony, only differences among coral colonies and genotypes were statistically significant. However, the effect size was small, as almost every sample had high relative abundances of sequences classified as the Rickettsiales genus MD3-55 (Candidatus Aquarickettsia rohweri). To date, this presumably parasitic intracellular bacterium has been associated with white-band disease, although direct evidence of a negative relationship between genus MD3-55 and its coral hosts is lacking. Here, high relative abundances of MD3-55 were found in corals showing no signs of diseases over more than 2 years of monitoring. In addition, we detected a striking pattern of unique amplicon sequence variants of MD3-55 associated with different coral genotypes, suggesting that these strains may have functional differences selected by the host. Future work incorporating both physiological and genomic analysis of these bacteria is required to fully elucidate the role of MD3-55 bacteria in A. cervicornis corals.

\section{References}

1. Goreau TF. The ecology of Jamaican coral reefs I. Species composition and zonation. Ecology. 1959;40:67-90.

2. Bellwood DR, Hughes TP, Folke C, Nyström M. Confronting the coral reef crisis. Nature. 2004;429:827-33.

3. Pandolfi JM, Jackson JBC. Ecological persistence interrupted in Caribbean coral reefs. Ecol Lett. 2006;9:818-26.

4. Boulon R, Chiappone M, Halley R, Jaap W, Keller B, Kruczynski B, Miller M, Rogers C. Atlantic Acropora status review document: Report to national marine fisheries service, southeast regional office [Internet]. 2005 Mar. Available from: 
400

401

402

403

404

405

406

407

408

409

410

411

412

413

414

415

416

417

418

419

420

421

422

423

424

425

426

427

428

429

430

431

432

433

434

435

436

437

438

439

440

441

442

443

444

445

http://www.reefrelieffounders.com/science/wp-content/uploads/2010/01/Atlantic-

Acropora-Status-Review-March-3-2005.pdf

5. Aronson RB, Precht WF. White-band disease and the changing face of Caribbean coral reefs. In: Porter JW, editor. The Ecology and Etiology of Newly Emerging Marine Diseases. Dordrecht: Springer Netherlands; 2001. p. 25-38.

6. Aronson R, Bruckner A, Moore J, Precht B, Weil E. Acropora cervicornis. The IUCN Red List of Threatened Species 2008: e. T133381A3716457. 2008.

7. Hogarth WT. Endangered and threatened species: final listing determinations for elkhorn coral and staghorn coral. Fed Regist. 2006;71:26852-61.

8. Bayraktarov E, Banaszak A, Montoya Maya PH, Kleypas J, Arias-Gonzalez JE, Blanco M, Calle J, Charuvi N, Useche CC, Galvan VM, Garcia Salgado MA, Gnecco M, Guendulain Garcia SD, Hernandex Delgado EA, Marin Morga JA, Maya MF, Quiroz SM, Cervantes SM, Morikawa M, Nava G, Pizarro V, Sellares-Blasco RI, Suleiman Ramos SE, Cubero TV, Villalpando M, Frias-Torres S. Coral reef restoration efforts in Latin American countries and territories [Internet]. bioRxiv. 2020 [cited $2020 \mathrm{Feb}$ 18]. p. 2020.02.16.950998. Available from: https://www.biorxiv.org/content/10.1101/2020.02.16.950998v1

9. Young CN, Schopmeyer SA, Lirman D. A review of reef restoration and coral propagation using the threatened genus Acropora in the Caribbean and Western Atlantic. Bull Mar Sci 2012; 88: 1075-1098.

10. Schopmeyer SA, Lirman D, Bartels E, Gilliam DS, Goergen EA, Griffin SP, Johnson ME, Lustic C, Maxwell K, Walter CS. Regional restoration benchmarks for Acropora cervicornis. Coral Reefs. 2017;36:1047-57.

11. Lirman D, Schopmeyer S. Ecological solutions to reef degradation: optimizing coral reef restoration in the Caribbean and Western Atlantic. PeerJ. 2016;4:e2597.

12. Lirman D, Schopmeyer S, Galvan V, Drury C, Baker AC, Baums IB. Growth dynamics of the threatened Caribbean staghorn coral Acropora cervicornis: influence of host genotype, symbiont identity, colony size, and environmental setting. PLoS One. 2014;9:e107253.

13. Gignoux-Wolfsohn SA, Marks CJ, Vollmer SV. White Band Disease transmission in the threatened coral, Acropora cervicornis. Sci Rep 2012; 2: 804.

14. Sussman M, Loya Y, Fine M, Rosenberg E. The marine fireworm Hermodice carunculata is a winter reservoir and spring-summer vector for the coral-bleaching pathogen Vibrio shiloi. Environ Microbiol 2003; 5: 250-255.

15. Mercado-Molina AE, Ruiz-Diaz CP, Sabat AM. Survival, growth, and branch production of unattached fragments of the threatened hermatypic coral Acropora cervicornis. J Exp Mar Bio Ecol. 2014;457:215-9.

16. Ladd MC, Shantz AA, Nedimyer K, Burkepile DE. Density dependence drives habitat production and survivorship of Acropora cervicornis used for restoration on a Caribbean coral reef. Frontiers in Marine Science. 2016;3:261.

17. Lohr KE, Patterson JT. Intraspecific variation in phenotype among nursery-reared staghorn coral Acropora cervicornis (Lamarck, 1816). J Exp Mar Bio Ecol. 2017;486:8792.

18. Johnson M. Staghorn coral, Acropora cervicornis, restoration in South Florida: growth and survivorship of outplanted nursery corals [Internet]. Nova Southeastern University; 2015 [cited 2019 Jan 14]. Available from: http://nsuworks.nova.edu/occ_stuetd/384/ 
446

447

448

449

450

451

452

453

454

455

456

457

458

459

460

461

462

463

464

465

466

467

468

469

470

471

472

473

474

475

476

477

478

479

480

481

482

483

484

485

486

487

488

489

490

491

19. Miller MW, Colburn PJ, Pontes E, Williams DE, Bright AJ, Serrano XM, Peters EC. Genotypic variation in disease susceptibility among cultured stocks of elkhorn and staghorn corals. PeerJ. 2019;7:e6751.

20. Ladd MC, Shantz AA, Bartels E, Burkepile DE. Thermal stress reveals a genotypespecific tradeoff between growth and tissue loss in restored Acropora cervicornis. Mar Ecol Prog Ser. 2017;572:129-39.

21. Goergen EA, Gilliam DS. Outplanting technique, host genotype, and site affect the initial success of outplanted Acropora cervicornis. PeerJ. 2018;6:e4433.

22. Goergen EA, Ostroff Z, Gilliam DS. Genotype and attachment technique influence the growth and survival of line nursery corals. Restor Ecol. 2018;26:622-8.

23. Bourne DG, Garren M, Work TM, Rosenberg E, Smith GW, Harvell CD. Microbial disease and the coral holobiont. Trends Microbiol. 2009;17:554-62.

24. Bourne DG, Morrow KM, Webster NS. Insights into the coral microbiome: underpinning the health and resilience of reef ecosystems. Annu Rev Microbiol. 2016;70:317-40.

25. Krediet CJ, Ritchie KB, Paul VJ, Teplitski M. Coral-associated micro-organisms and their roles in promoting coral health and thwarting diseases. Proc Biol Sci. 2013;280:20122328.

26. Peixoto RS, Rosado PM, Leite DC de A, Rosado AS, Bourne DG. Beneficial Microorganisms for Corals (BMC): proposed mechanisms for coral health and resilience. Front Microbiol. 2017;8:341.

27. Rosado PM, Leite DCA, Duarte GAS, Chaloub RM, Jospin G, Nunes da Rocha U, P. Saraiva J, Dini-Andreote F, Eisen JA, Bourne DG, Peixoto RS. Marine probiotics: increasing coral resistance to bleaching through microbiome manipulation. ISME J. 2018;13:921-36.

28. Rosenberg E, Koren O, Reshef L, Efrony R, Zilber-Rosenberg I. The role of microorganisms in coral health, disease and evolution. Nat Rev Microbiol. 2007;5:35562.

29. van Oppen MJH, Gates RD, Blackall LL, Cantin N, Chakravarti LJ, Chan WY, Cormick C, Crean A, Damjanovic K, Epstein H, Harrison PL, Jones TA, Miller M, Pears RJ, Peplow LM, Raftos DA, Schaffelke B, Stewart K, Torda G, Wachenfeld D, Weeks AR, Putnam HM. Shifting paradigms in restoration of the world's coral reefs. Glob Chang Biol. 2017;23:3437-48.

30. West AG, Waite DW, Deines P, Bourne DG, Digby A, McKenzie VJ, Taylor MW. The microbiome in threatened species conservation. Biol Conserv. 2019;229:85-98.

31. van Oppen MJH, Blackall LL. Coral microbiome dynamics, functions and design in a changing world. Nat Rev Microbiol 2019; 17: 557-5467.

32. Sweet MJ, Bulling MT. On the Importance of the Microbiome and Pathobiome in Coral Health and Disease. Frontiers in Marine Science 2017; 4: 9.

33. Rädecker N, Pogoreutz C, Voolstra CR, Wiedenmann J, Wild C. Nitrogen cycling in corals: the key to understanding holobiont functioning? Trends Microbiol 2015; 23: 490497.

34. Peixoto RS, Sweet M, Bourne DG. Customized Medicine for Corals. Frontiers in Marine Science 2019; 6: 686.

35. Damjanovic K, Blackall LL, Webster NS, van Oppen MJH. The contribution of microbial biotechnology to mitigating coral reef degradation. Microb Biotechnol 2017; 10: 12361243.

Peer) reviewing PDF | (2020:04:48378:1:1:NEW 3 Jul 2020) 
492

493

494

495

496

497

498

499

500

501

502

503

504

505

506

507

508

509

510

511

512

513

514

515

516

517

518

519

520

521

522

523

524

525

526

527

528

529

530

531

532

533

534

535

536
36. Rohwer F, Seguritan V, Azam F, Knowlton N. Diversity and distribution of coralassociated bacteria. Mar Ecol Prog Ser. 2002;243:1-10.

37. Daniels CA, Zeifman A, Heym K, Ritchie KB, Watson CA, Berzins I, Breitbart M. Spatial heterogeneity of bacterial communities in the mucus of Montastraea annularis. Mar Ecol Prog Ser. 2011;426:29-40.

38. Kemp DW, Rivers AR, Kemp KM, Lipp EK, Porter JW, Wares JP. Spatial homogeneity of bacterial communities associated with the surface mucus layer of the reef-building coral Acropora palmata. PLoS One. 2015;10:e0143790.

39. Godoy-Vitorino F, Ruiz-Diaz CP, Rivera-Seda A, Ramírez-Lugo JS, Toledo-Hernández C. The microbial biosphere of the coral Acropora cervicornis in Northeastern Puerto Rico. PeerJ. 2017;5:e3717.

40. Chu ND, Vollmer SV. Caribbean corals house shared and host-specific microbial symbionts over time and space. Environ Microbiol Rep. 2016;8:493-500.

41. Gignoux-Wolfsohn SA, Aronson FM, Vollmer SV. Complex interactions between potentially pathogenic, opportunistic, and resident bacteria emerge during infection on a reef-building coral. FEMS Microbiol Ecol 2017; 93.

42. Drury C, Schopmeyer S, Goergen E, Bartels E, Nedimyer K, Johnson M, Maxwell K, Galvan V, Manfrino C, Lirman D. Genomic patterns in Acropora cervicornis show extensive population structure and variable genetic diversity. Ecol Evol. 2017;7:6188200.

43. Salter SJ, Cox MJ, Turek EM, Calus ST, Cookson WO, Moffatt MF, Turner P, Parkhill J, Loman NJ, Walker AW. Reagent and laboratory contamination can critically impact sequence-based microbiome analyses. BMC Biol 2014; 12: 87.

44. Caporaso JG, Lauber CL, Walters WA, Berg-Lyons D, Lozupone CA, Turnbaugh PJ, Fierer N, Knight R. Global patterns of $16 \mathrm{~S}$ rRNA diversity at a depth of millions of sequences per sample. Proc Natl Acad Sci U S A. 2011;108 Suppl 1:4516-22.

45. Parada AE, Needham DM, Fuhrman JA. Every base matters: assessing small subunit rRNA primers for marine microbiomes with mock communities, time series and global field samples. Environ Microbiol. 2016;18:1403-14.

46. Apprill A, McNally S, Parsons R, Weber L. Minor revision to V4 region SSU rRNA 806R gene primer greatly increases detection of SAR11 bacterioplankton. Aquat Microb Ecol. 2015;75:129-37.

47. Martin M. Cutadapt removes adapter sequences from high-throughput sequencing reads. EMBnet.journal. journal.embnet.org; 2011;17:10-2.

48. Callahan BJ, McMurdie PJ, Rosen MJ, Han AW, Johnson AJA, Holmes SP. DADA2: High-resolution sample inference from Illumina amplicon data. Nat Methods. 2016;13:581-3.

49. Meyer JL, Castellanos-Gell J, Aeby GS, Häse CC, Ushijima B, Paul VJ. Microbial community shifts associated with the ongoing stony coral tissue loss disease outbreak on the Florida Reef Tract. Frontiers in Microbiology. 2019;10:2244.

50. Yilmaz P, Parfrey LW, Yarza P, Gerken J, Pruesse E, Quast C, Schweer T, Pepiles J, Ludwig W, Glöckner FO. The SILVA and "All-species Living Tree Project (LTP)" taxonomic frameworks. Nucleic Acids Res. 2014;42:D643-8.

51. McMurdie PJ, Holmes S. phyloseq: an R package for reproducible interactive analysis and graphics of microbiome census data. PLoS One. 2013;8:e61217. 
537

538

539

540

541

542

543

544

545

546

547

548

549

550

551

552

553

554

555

556

557

558

559

560

561

562

563

564

565

566

567

568

569

570

571

572

573

574

575

576

577

578

579

580

581
52. Palarea-Albaladejo J, Martín-Fernández JA. zCompositions-R package for multivariate imputation of left-censored data under a compositional approach. Chemometrics Intellig Lab Syst. Elsevier; 2015;143:85-96.

53. Gloor GB, Wu JR, Pawlowsky-Glahn V, Egozcue JJ. It's all relative: analyzing microbiome data as compositions. Ann Epidemiol. 2016;26:322-9.

54. Wickham H. ggplot2: Elegant Graphics for Data Analysis. Springer; 2016.

55. Dixon P. VEGAN, a package of R functions for community ecology. J Veg Sci. 2003;14:927-30.

56. Mandal S, Van Treuren W, White RA, Eggesbø M, Knight R, Peddada SD. Analysis of composition of microbiomes: a novel method for studying microbial composition. Microb Ecol Health Dis. 2015;26:27663.

57. Pantos O, Bythell JC. Bacterial community structure associated with white band disease in the elkhorn coral Acropora palmata determined using culture-independent 16S rRNA techniques. Dis Aquat Organ. 2006;69:79-88.

58. Roder C, Arif C, Bayer T, Aranda M, Daniels C, Shibl A, Chavanich S, Voolstra CR. Bacterial profiling of White Plague Disease in a comparative coral species framework. ISME J. 2014;8:31-9.

59. Sheu S-Y, Liu L-P, Tang S-L, Chen W-M. Thalassotalea euphylliae sp. nov., isolated from the torch coral Euphyllia glabrescens. Int J Syst Evol Microbiol. 2016;66:5039-45.

60. Webster NS, Uthicke S, Botté ES, Flores F, Negri AP. Ocean acidification reduces induction of coral settlement by crustose coralline algae. Glob Chang Biol. 2013;19:30315.

61. Bergman O, Haber M, Mayzel B, Anderson MA, Shpigel M, Hill RT, Ilan M. Marinebased cultivation of diacarnus sponges and the bacterial community composition of wild and maricultured sponges and their larvae. Mar Biotechnol . 2011;13:1169-82.

62. Sunagawa S, Woodley CM, Medina M. Threatened corals provide underexplored microbial habitats. PLoS One. 2010;5:e9554.

63. Séré MG, Tortosa P, Chabanet P, Turquet J, Quod J-P, Schleyer MH. Bacterial communities associated with Porites white patch syndrome (PWPS) on three western Indian Ocean (WIO) coral reefs. PLoS One. 2013;8:e83746.

64. Tang S-L, Hong M-J, Liao M-H, Jane W-N, Chiang P-W, Chen C-B, Chen CA. Bacteria associated with an encrusting sponge (Terpios hoshinota) and the corals partially covered by the sponge. Environ Microbiol. 2011;13:1179-91.

65. Klinges JG, Rosales SM, McMinds R, Shaver EC, Shantz AA, Peters EC, Eitel M, Wörheide G, Sharp KH, Burkepile DE, Silliman BR, Vega Thurber RL. Phylogenetic, genomic, and biogeographic characterization of a novel and ubiquitous marine invertebrate-associated Rickettsiales parasite, Candidatus Aquarickettsia rohweri, gen. nov., sp. nov. ISME J. 2019;13:2938-53.

66. Kimes NE, Johnson WR, Torralba M, Nelson KE, Weil E, Morris PJ. The Montastraea faveolata microbiome: ecological and temporal influences on a Caribbean reef-building coral in decline. Environ Microbiol. 2013;15:2082-94.

67. Sunagawa S, DeSantis TZ, Piceno YM, Brodie EL, DeSalvo MK, Voolstra CR, Weil E, Andersen GL, Medina M. Bacterial diversity and White Plague Disease-associated community changes in the Caribbean coral Montastraea faveolata. ISME J. 2009;3:51221 . 
582

583

584

585

586

587

588

589

590

591

592

593

594

595

596

597

598

599

600

601

602

603

604

605

606

607

608

609

610

611
68. Wilbanks EG, Jaekel U, Salman V, Humphrey PT, Eisen JA, Facciotti MT, Buckley DH, Zinder SH, Druschel GK, Fike DA, Orphan VJ. Microscale sulfur cycling in the phototrophic pink berry consortia of the Sippewissett Salt Marsh. Environ Microbiol. 2014;16:3398-415.

69. Foster JS, Green SJ, Ahrendt SR, Golubic S, Reid RP, Hetherington KL, Bebout L. Molecular and morphological characterization of cyanobacterial diversity in the stromatolites of Highborne Cay, Bahamas. ISME J. 2009;3:573-87.

70. Casas V, Kline DI, Wegley L, Yu Y, Breitbart M, Rohwer F. Widespread association of a Rickettsiales-like bacterium with reef-building corals. Environ Microbiol. 2004;6:113748.

71. Rosales SM, Miller MW, Williams DE, Traylor-Knowles N, Young B, Serrano XM. Microbiome differences in disease-resistant vs. susceptible Acropora corals subjected to disease challenge assays. Sci Rep. 2019;9:18279.

72. Shaver EC, Shantz AA, McMinds R, Burkepile DE, Vega Thurber RL, Silliman BR. Effects of predation and nutrient enrichment on the success and microbiome of a foundational coral. Ecology. 2017;98:830-9.

73. Peters EC, Oprandy JJ, Yevich PP. Possible causal agent of "white band disease" in caribbean acroporid corals. J Invertebr Pathol. 1983;41:394-6.

74. Miller MW, Lohr KE, Cameron CM, Williams DE, Peters EC. Disease dynamics and potential mitigation among restored and wild staghorn coral, Acropora cervicornis. PeerJ. 2014;2:e541.

75. Gignoux-Wolfsohn SA, Precht WF, Peters EC, Gintert BE, Kaufman LS. Ecology, histopathology, and microbial ecology of a white-band disease outbreak in the threatened staghorn coral Acropora cervicornis. Dis Aquat Organ. 2020;137:217-37.

76. Gignoux-Wolfsohn SA, Vollmer SV. Identification of candidate coral pathogens on white band disease-infected staghorn coral. PLoS One. 2015;10:e0134416.

77. Glasl B, Smith CE, Bourne DG, Webster NS. Disentangling the effect of host-genotype and environment on the microbiome of the coral Acropora tenuis. PeerJ 2019; 7: e6377.

78. Hester ER, Barott KL, Nulton J, Vermeij MJ, Rohwer FL. Stable and sporadic symbiotic communities of coral and algal holobionts. ISME J 2016; 10: 1157-1169. 


\section{Figure 1}

Nursery-reared Acropora cervicornis sampled in December 2017 for microbial community composition.

A) Three colonies each of red (R), green $(G)$, and yellow $(Y)$ coral genotypes were sampled. B) On each colony, three replicate samples were collected on basal branches $\left(1^{\circ}\right)$, intermediate branches $\left(2^{\circ}\right)$, and apical colony tips $\left(3^{\circ}\right)$. C) The same colonies photographed in October 2018 showed rapid growth and no signs of disease. Acropora cervicornis icon courtesy of the Integration and Application Network, University of Maryland Center for Environmental Science (ian.umces.edu/symbols/).
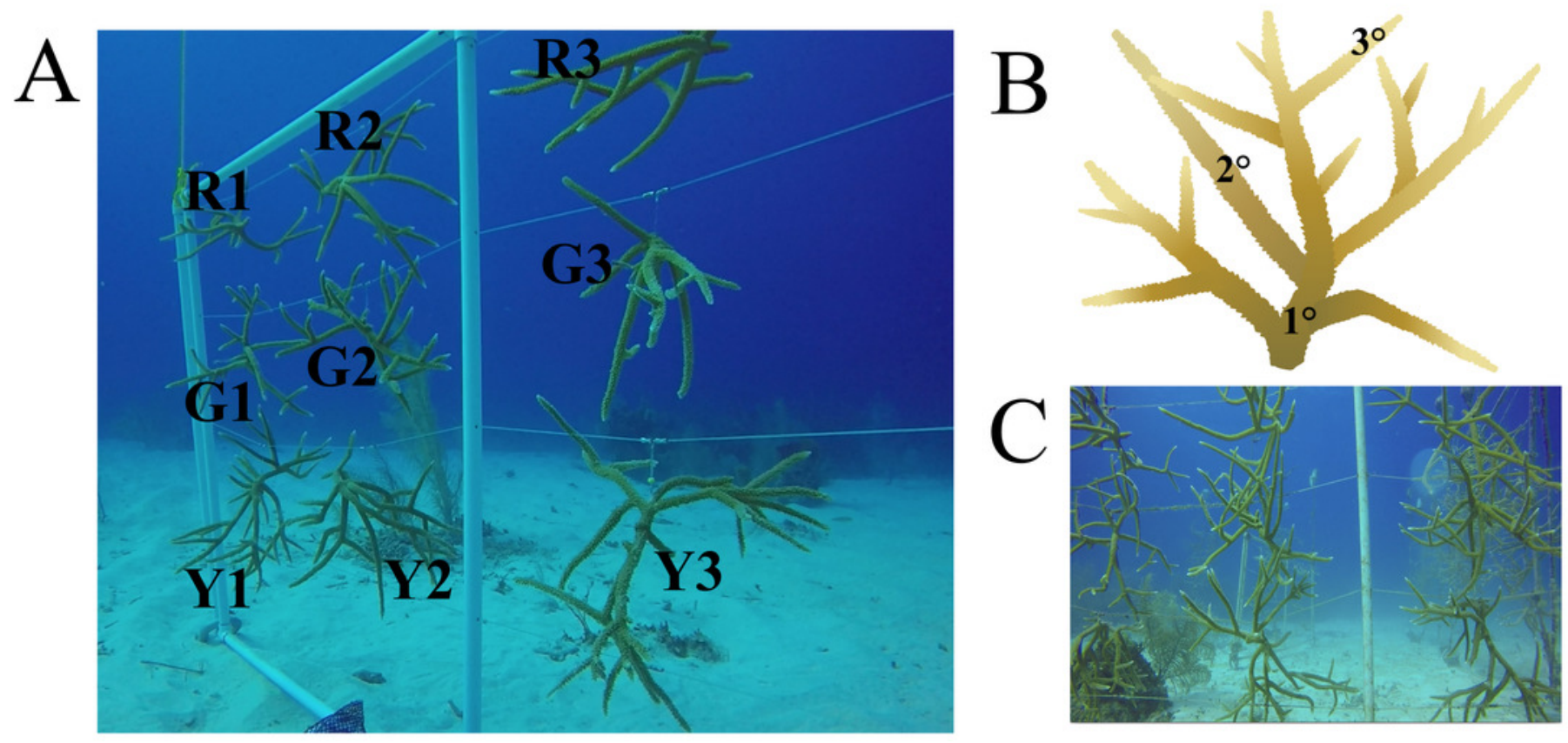
Figure 2

Principal Component Analysis of the Aitchison distance between microbial communities from green $(G)$, red $(R)$, and yellow $(Y)$ genotypes of nursery-reared Acropora cervicornis.

Location of samples within individual colonies are indicated by symbol shape. Principal Component 1 (PC1) explained $24 \%$ of the variation among communities and Principal Component 2 (PC2) explained $8 \%$ of the variation among communities.

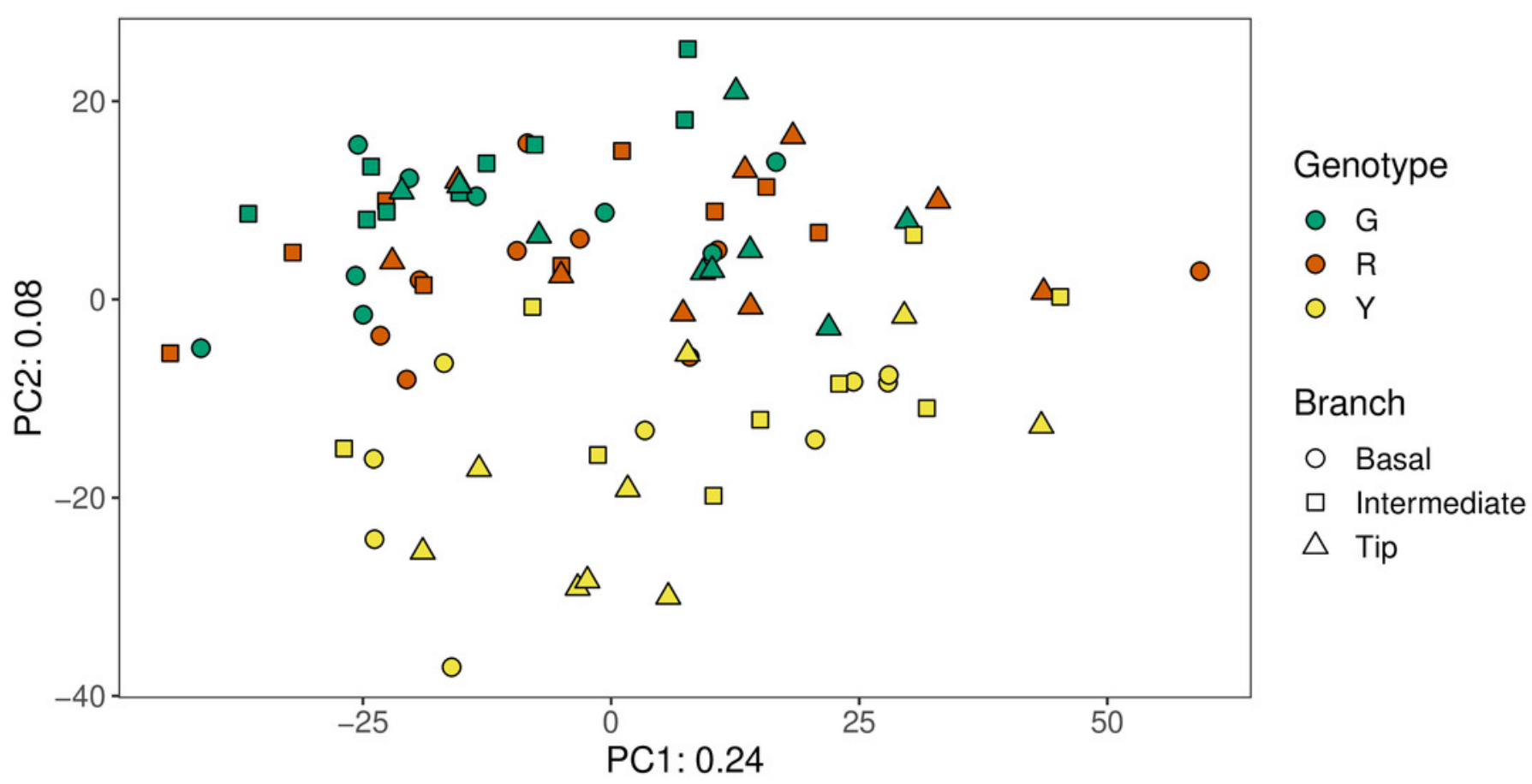


Figure 3

Relative abundance of amplicon sequence variants of the V4 region of 16S rRNA genes in nursery-reared Acropora cervicornis, colored by bacterial order.

Samples are grouped by coral genotype: $(A)$ green $(G),(B)$ red $(R)$, and $(C)$ yellow $(Y)$ and by location within the colony: basal branches $\left(1^{\circ}\right)$, intermediate branches $\left(2^{\circ}\right)$, and apical colony tips $\left(3^{\circ}\right)$. 

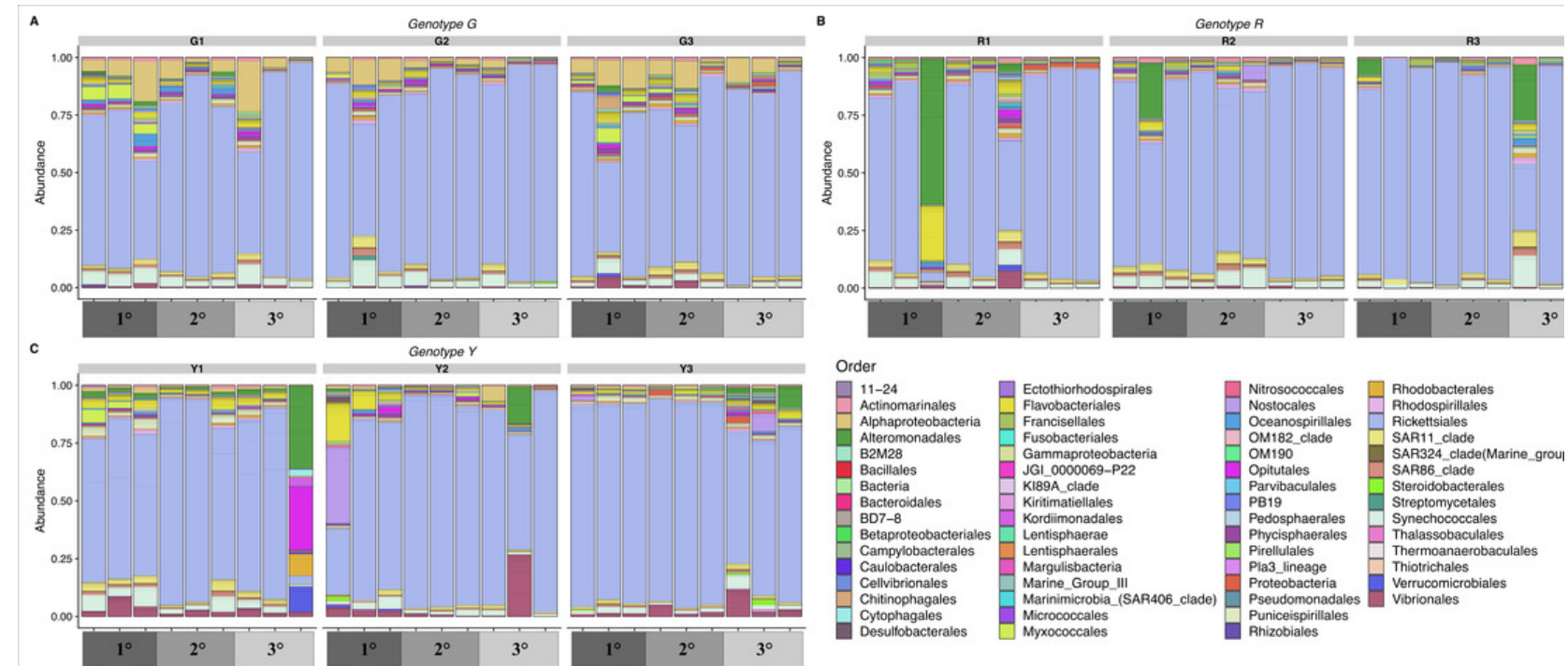

Rhodobacterales
Rhodospirillales Rickettsiales SAR324_clade(Marine gro AAR66 clade Steroidobacterales Streptomycetales Synechococcales
halassobaculales Thermoanaerobaculales Thiotrichales Vertucomicrobia
Vibrionales vibrionales Puniceispirillales 


\section{Figure 4}

Proportion of amplicon sequence variants classified as the Rickettsiales genus MD3-55 relative to all ASVs in the communities in colonies of green $(G)$, red $(R)$, and yellow $(Y)$ coral genotypes of nursery-reared Acropora cervicornis.

Each bar represents one sample, with a total of nine samples per coral colony.

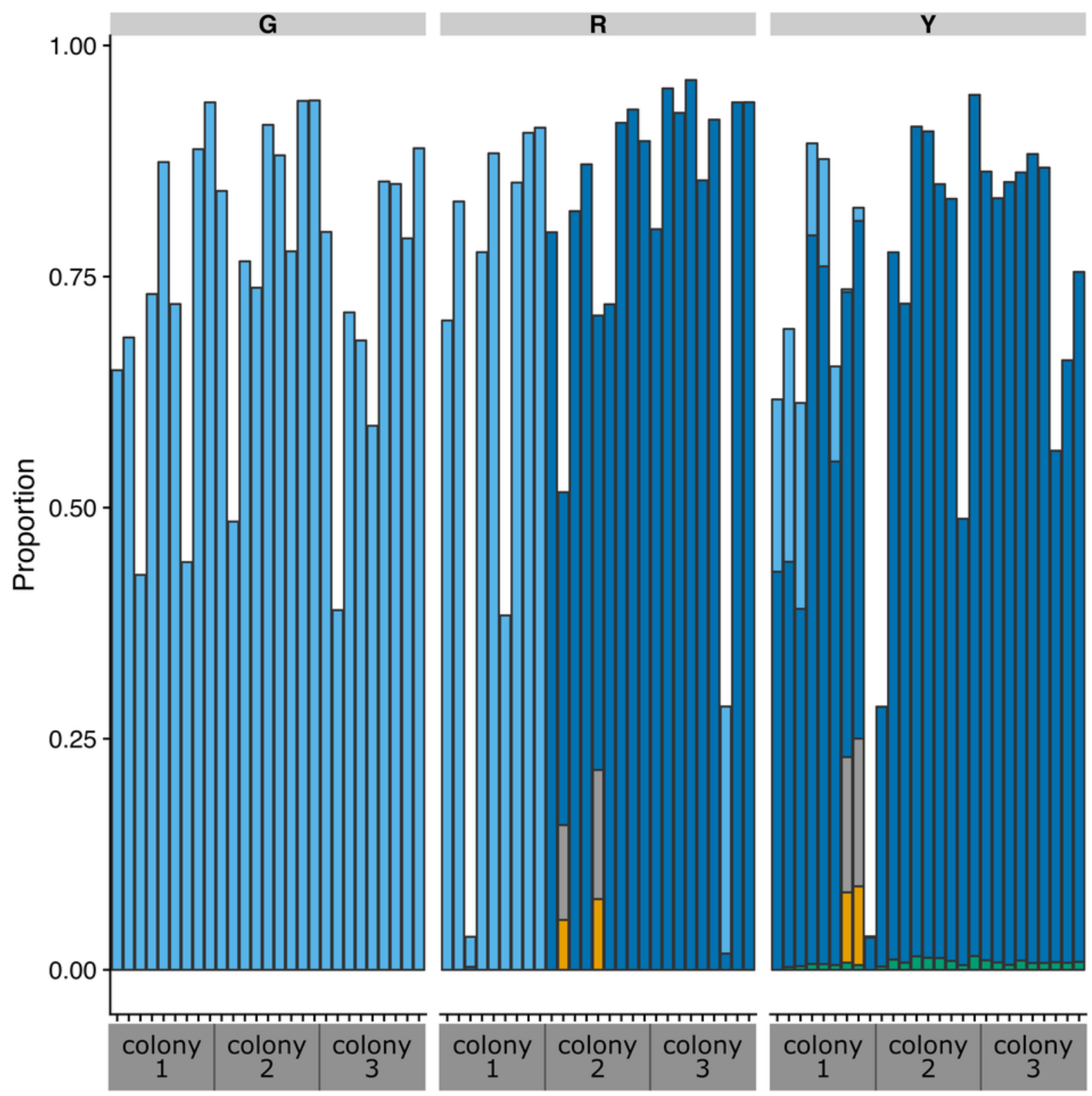


Figure 5

Relative abundance of amplicon sequence variants in differentially abundant families between colonies of green $(G)$, red $(R)$, and yellow $(Y)$ coral genotypes of nursery-reared Acropora cervicornis.

To increase separation of very small values, relative abundances are plotted on a log scale, with 0.001 added to every value to avoid taking the log of zero.

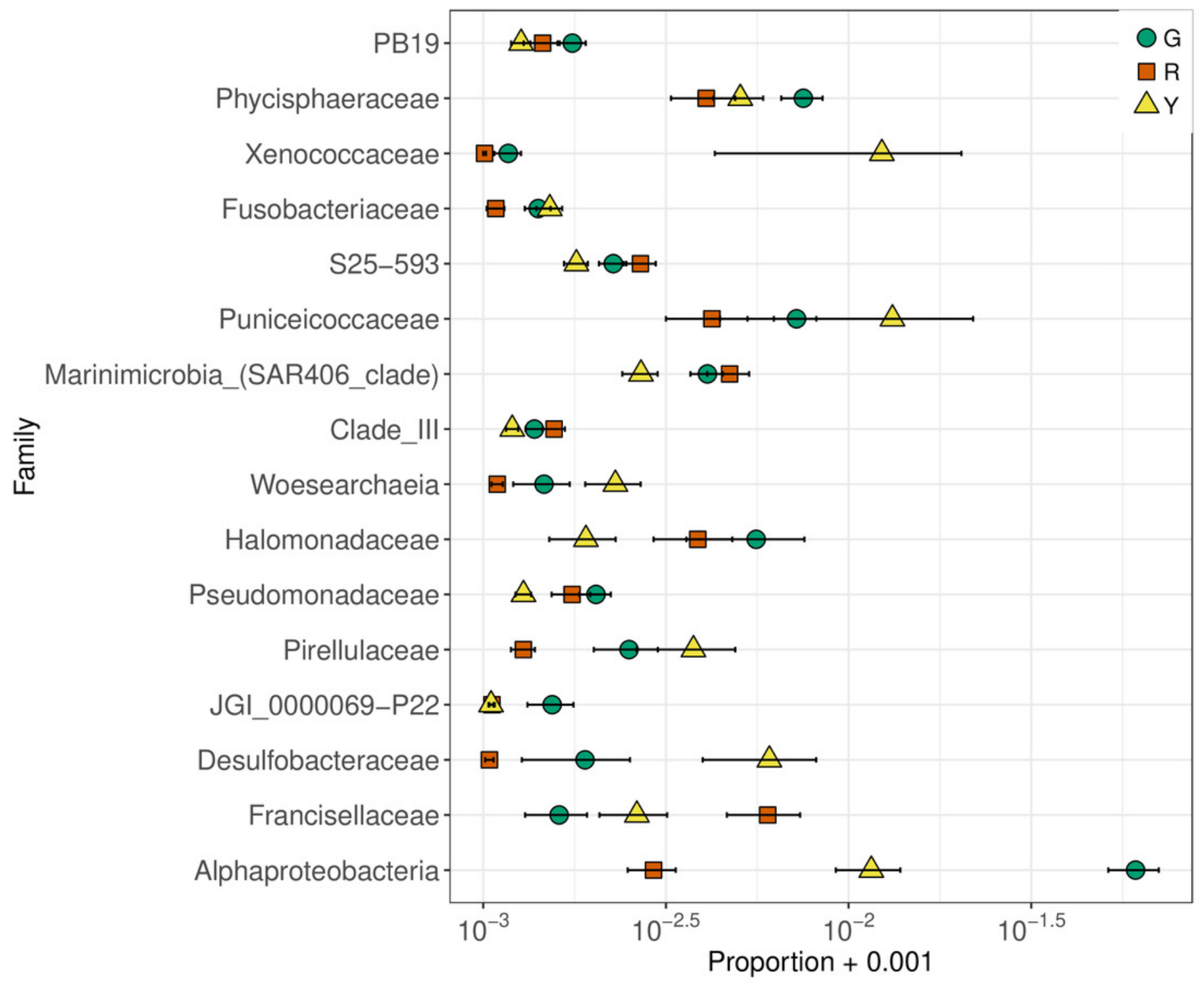

